\title{
Hydrolysis of Palm Tree Midribs with Hydrochloric Acid for Furfural Formation
}

\author{
Hisham S. Bamufleh \\ Department of Chemical \& Materials Engineering, Faculty of Engineering, King Abdulaziz \\ University, P.O. Box 80204, Jeddah, 21589, Saudi Arabia \\ hbamufleh@kau.edu.sa
}

\begin{abstract}
Waste material samples as pentosan source of midribs from the Sukkaria date palm tree were collected from different Saudi Arabian agricultural areas, and hydrolyzed using hydrochloric acid $(\mathrm{HCl})$ to produce furfural at different temperatures, liquid to solid ratios (LSR) and acid concentrations. A maximum furfural production with a concentration of $755 \mathrm{gm} / \mathrm{m}^{3}$ ( $72 \%$ furfural yield) was achieved, which was close to the theoretical yield at $15 \mathrm{wt} \% \mathrm{HCl}$ and $100 \mathrm{ml} / \mathrm{g} \mathrm{LSR}$ at $120^{\circ} \mathrm{C}$. The kinetic model for the pentosan fractional hydrolysis towards the production of furfural was previously proposed and developed. Regression analysis of the experimental data was successfully performed using Ploymath software with acceptable predictions precision and regression coefficients of $\mathrm{R}^{2} \geq 0.96$. Furthermore, regressed rate constants of each reaction step in the proposed kinetic model were developed using modified Arrhenius model with an acceptable accuracy of $\mathrm{R}^{2} \geq 0.96$. Experimental data showed that hydrolysis using hydrochloric acid could achieve higher furfural yields with lower reaction times in comparison with sulfuric acid hydrolysis, due to lower activation energy of the involved steps.
\end{abstract}

Keywords: Furfural, Palm tree midribs, Hydrochloric acid, Hydrolysis.

\section{Introduction}

The industrial applications of furfural and its derivatives have gained more importance as strategic commodities ${ }^{[1]}$ since it is a feedstock for many chemical products. Furfuryl alcohol that is derived by furfural hydrogenation can be used in the production of furan resin and cement materials, which are characterized by their high structural resistances, as well as heat transfer properties ${ }^{[2-4]}$. Furfural can be used to produce biofuels and value-added chemicals ${ }^{[5-6]}$. Also, it is mainly used as an effective solvent that selectively dissolves and separates aromatics and olefins in oil refineries [1]. Furfural has other important applications in the production of the key product tetrahydrofuran
(THF) and can be used also as a fungicide and herbicide ${ }^{[7]}$.

The main source of furfural production is the hydrolysis in acidic media of the lignocelluloses biomass and hemicelluloses with high pentosan content available in some agriculture residues, such as palm tree midribs ${ }^{[8]}$, olive trees ${ }^{[9]}$, sorghum straw ${ }^{[10]}$ and timber [11]. It can be produced also from food processing plant waste, such as sugar cane bagasse ${ }^{[12]}$, olive stones ${ }^{[13]}$, corncobs ${ }^{[14]}$ and rice hulls ${ }^{[1]}$.

Mineral acids were used as a catalyst for hydrolyzing biomass waste materials to produce furfural. Among these acids are 
hydrochloric acid $(\mathrm{HCl})^{[15]}$, nitric acid $\left(\mathrm{HNO}_{3}\right)^{[16]}$, sulfuric acid $\left(\mathrm{H}_{2} \mathrm{SO}_{4}\right)^{[17]}$, and phosphoric acid $\left(\mathrm{H}_{3} \mathrm{PO}_{4}\right)^{[18]}$.

The higher the hydrolysis pressures (1025 bar) and temperatures $\left(220-240^{\circ} \mathrm{C}\right)$ the higher furfural yields ${ }^{[19]}$ and shorter reaction times ${ }^{[20-21]}$ are. Alternatively, furfural can be formed from hemi-cellulosic materials using the acidic ionic liquid (ILs) characterized by their low vapor pressures and flammability, low temperature sensitivity and high solubility with $60-70 \%$ furfural yield ${ }^{[22]}$. The catalytic coproduction of furfural and the important byproduct 5 hydroxymethyl furfural, 5HMF, has been investigated to improve the economic feasibility of the production process ${ }^{[23-27]}$. Metal oxides as solid acid catalysts and sulfonated biomass carbon materials have increasingly attracted researchers' attention, due to their strong acidity, high active surface area and low temperature sensitivity [28]. Furthermore, furfural was produced using alginic acid derived from macroalgae over Amberlyst-15 solid acid catalyst ${ }^{[29]}$. However, ILs and solid catalysts are currently expensive and difficult to synthesize. More extensive research is required to improve their performance. Additionally, the economic feasibility of their industrial synthesis process must be considered.

Hydrolysis of pentosan to pentose takes place in acidic solutions as catalysts to accelerate the dissociation of pentosan molecules, which is dehydrated in a subsequent step to furfural. The actual furfural yield that can be obtained is $50-65 \%$, which is dependent on the hydrolysis reaction temperature and acid concentration ${ }^{[21]}$, while the maximum reported furfural theoretical yield is $72.7 \%{ }^{[7]}$.

Due to the complexity of the liquid phase hydrolysis reactions of solid phase lignocelluloses feedstocks [30], many investigators proposed reaction steps and used simplified empirical expressions to model the kinetics parameters for each reaction step ${ }^{[31]}$. Both dilute and concentrated acid hydrolysis can be used to hydrolyze hemicellulose cellulose fractions ${ }^{[9]}$.

Agriculture wastes are abundantly available with low cost and suitable to produce value-added products. They must be disposed properly. All these factors increase the opportunity of lignocellulosic materials to provide an alternative energy source ${ }^{[9,30]}$. Saudi Arabia has tremendous quantities of date palm trees. Therefore, it would be more attractive to investigate alternatives that utilize these abundant date palms to produce valueadded products, such as furfural and its derivatives.

Recently, we have studied the kinetics and yields of furfural production by hydrolyzing midribs using sulfuric acid ${ }^{[8]}$. Hydrolysis of lignocellulosic agricultural wastes using hydrochloric acid resulted in a higher yield of furfural as compared to sulfuric acid at the same temperature and acid concentration conditions ${ }^{[32]}$. Hydrochloric acid is capable of hydrolyzing and breaking the hemi cellulosic biomass materials more easily and efficiently than sulfuric acid ${ }^{[33]}$. Therefore, the purpose of the present work is to study the formation of furfural through the hydrolysis process of the local palm tree midribs, using hydrochloric acid instead of sulfuric acid, which was used in previous work. The key operating parameters of the process, namely reaction temperature, liquid to solid ratio, acid concentration and reaction time were investigated to determine the optimum conditions based on the maximum furfural yield. The obtained experimental data were fit in the previously proposed kinetic model of the hydrolysis reaction to evaluate the derived model. 


\section{Experimental Procedures}

\subsection{Raw Materials Preparation and Characterization}

Sukkaria palm tree was selected, and midrib samples were collected from agricultural areas in Saudi Arabia. Samples were prepared for analysis and hydrolysis reaction as reported in Bamufleh et al. ${ }^{[8]}$. In this previous study midrib samples were characterized for pentosan content using Association of Official Analytical Chemists AOAC-36D.

\subsection{Hydrolysis Reaction}

$1500 \mathrm{ml}$ and maximum 10 bars pressure Parr batch glass reactor (5112 model) jacketed and stirred, manufactured by Hastelloy B2 and stainless steel, was used in the hydrolysis reaction. The required acid volume of a given concentration and required raw material with given liquid to solid ratio (LSR) were placed in the reactor. Reaction time was recorded and samples were collected for chemical analysis at specific time intervals. Three values of acid concentrations of 5,10 , and $15 \mathrm{wt} \%$, LSR of 25, 50, and $100 \mathrm{ml} / \mathrm{g}$, and reaction temperatures of 100,120 , and $160^{\circ} \mathrm{C}$ were experimentally carried out. Detailed reaction procedures were reported in the reference ${ }^{[8]}$.

\subsection{Product Analysis}

Most articles were likely to have only two levels of headings. $20 \mu \mathrm{l}$ of periodically collected samples, filtered and diluted with water $(1: 100 \mathrm{v} / \mathrm{v})$ were injected via a liquid sampling valve for analysis into a Shimadzu HPLC unit. The column $4.6 \mathrm{~mm}$ i.d. x $50 \mathrm{~mm}$ Shim-Pack XR-ODS was used to investigate the hydrolysis reaction products. A carrier liquid with a composition of $84 \%$ of $0.01 \mathrm{~N}$ $\mathrm{H}_{2} \mathrm{SO}_{4}$ and $16 \%$ of acetonitrile was utilized. Flow rate of $0.5 \mathrm{ml} / \mathrm{min}$ at $4.9 \mathrm{Mpa}$ was regulated during the analysis. The following equation was used to calculate furfural yield:

$$
\text { Yield }=Y_{a c t} / Y_{t h} \times 100
$$

Where $Y_{a c t}$ is the experimental yield (gm) and $Y_{t h}$ is the theoretical yield (gm) when reaction of pentosan to furfural is achieved with $100 \%$ conversion. These two yields were calculated as follows:

$$
\begin{gathered}
Y_{a c t}=C \times V \\
Y_{t h}=\left(\mathrm{Mwt}_{\mathrm{F}} / \mathrm{Mwt}_{\mathrm{P}}\right) \times(\% \mathrm{P} / 100) \times \mathrm{W}
\end{gathered}
$$

Where $C$ is the experimental furfural concentration $\left(\mathrm{gm} / \mathrm{m}^{3}\right), \quad V$ is the mixture volume $\left(\mathrm{m}^{3}\right), \mathrm{W}$ is the midrib sample mass (gm), \% P is the pentosan wt $\%$ available in the midrib, $\mathrm{Mwt}_{\mathrm{F}}$ and $\mathrm{Mwt}_{\mathrm{P}}$ are the furfural and pentosan molecular weights, respectively.

\section{Kinetics Model}

Based on reported literature complexity of the lignocellulosic materials, hydrolysis reactions kinetics were simplified by proposing pseudo-homogenous first order irreversible reactions $[9,15,30]$. This approach was applied with the assumption that a fraction of pentosan in the raw material was easy and fast to hydrolyze, while the remaining pentosan fraction was difficult and slow to hydrolyze. Accordingly, the parameter $\alpha$ was introduced in the kinetic model as the fastdecomposed mass fraction of pentosan ${ }^{[13,31]}$. The first reaction started with the formation of pentose from pentosan, then progressively continued to other undesired decomposition products, as shown below ${ }^{[9,15,30,31]}$.

Pentosan (s) $\stackrel{k_{1}}{\rightarrow}$ Pentose (aq) $\stackrel{k_{2}}{\rightarrow}$ Furfural (aq) $\stackrel{k_{4}}{\rightarrow}$ Decomposition products (aq)

$$
\searrow^{k_{3}} \text { Decomposition products (aq) }
$$

Where $\mathrm{k}_{1}, \mathrm{k}_{2}, \mathrm{k}_{3}$ and $\mathrm{k}_{4}$ are the rate constants in $\left(\min ^{-1}\right)$. The previously derived kinetic model of the differential equations describing the above reactions system was as follows ${ }^{[8]}$ :

$$
\begin{gathered}
C_{P}=\alpha C_{P 0} e^{-k_{1} t} \\
C_{S}=\frac{\alpha k_{1} C_{P 0}}{\left(k_{2}+k_{3}\right)-k_{1}}\left(e^{-k_{1} t}-e^{-\left(k_{2}+k_{3}\right) t}\right)
\end{gathered}
$$


$C_{F}=$

$\frac{\alpha k_{1} k_{2} C_{P 0}}{\left(k_{2}+k_{3}\right)-k_{1}}\left(\frac{e^{-k_{1} t}-e^{-k_{4} t}}{k_{4}-k_{1}}-\frac{e^{-\left(k_{2}+k_{3}\right) t}-e^{-k_{4} t}}{k_{4}-\left(k_{2}+k_{3}\right)}\right)$

Where $C_{P}$ is the concentration of pentosane, $C_{P 0}$ is the initial concentration of pentosan in the raw material, $C_{S}$ is the concentration of pontose, $C_{F}$ is the furfural concentration (mol/liter) and $\mathrm{t}$ is hydrolysis time ( $\mathrm{min}$ ).

\section{Experimental Data Analysis}

\subsection{Characterization of Midribs}

Midribs' pentosan content was determined in the previous study by Bamufleh et al. ${ }^{[8]}$ as $14.52 \mathrm{wt} \%$ providing a reasonable amount of pentosan in comparison to that available in other reported lignocellulosic materials employed as raw materials for furfural production.

\subsection{Furfural Production}

Various conditions of acid concentration, reaction temperature and LSR of the hydrolysis reaction were selected to study their parametric effects on furfural concentration and yield. The experimental results were analyzed and discussed in the following subsections.

\subsection{Acid Concentration Parameter}

Hydrolysis reactions were carried out at acid concentrations of 5, 10 and $15 \mathrm{wt} \%$, at a LSR of 100 and a temperature of $120^{\circ} \mathrm{C}$. Furfural concentrations at various elapsed times were plotted, as shown in (Fig. 1). As shown in this figure, higher furfural yields were obtained at faster times with higher acid concentrations. Figure 1 shows clearly that for $15 \%$ acid concentration maximum furfural concentration is achieved faster at $755 \mathrm{gm} / \mathrm{m}^{3}$ in 10 mins compared to $5 \%$ and $10 \%$ with maximum furfural concentrations at 640 $\mathrm{gm} / \mathrm{m}^{3}$ in $210 \mathrm{~min}$ and $700 \mathrm{gm} / \mathrm{m}^{3}$ in $60 \mathrm{~min}$ respectively. Furfural concentration started to decrease after reaching its maximum value, the point beyond which the rate of furfural production was expected to be less than the rate of furfural decomposition. The first point with $10 \mathrm{wt} \%$ acid didn't fall in the same trend with the rest of the points and it occurs in the early stage of the main reactions toward furfural production. It is apparently due to other rapid side reaction(s) that proceed to produce furfural and other side products.

\subsection{Reaction Temperature Parameter}

Hydrolysis reactions at temperatures of 100, 120 and $160{ }^{\circ} \mathrm{C}$, at $10 \%$ acid concentration and $50 \mathrm{ml} / \mathrm{g}$ LSR were shown in Fig. 2. Data in this figure indicated that the maximum concentration of $1266 \mathrm{gm} / \mathrm{m}^{3}$ (a maximum furfural yield of $60 \%$ ) was obtained at $120^{\circ} \mathrm{C}$ after 60 minutes of hydrolysis, after which it decreased rapidly, because the furfural loss rate was much faster than the formation rate. Increasing the reaction temperature from $100^{\circ} \mathrm{C}$ to $120^{\circ} \mathrm{C}$ increased the obtained furfural concentrations, indicating that higher furfural concentration and yield were favored by higher temperatures within this range. On the other hand, increasing the reaction temperature to $160^{\circ} \mathrm{C}$, a maximum furfural concentration value of $400 \mathrm{gm} / \mathrm{m}^{3}$ (a maximum furfural yield of 19\%) was obtained after 5 minutes hydrolysis time compared to $1266 \mathrm{gm} / \mathrm{m}^{3}$ (a maximum furfural yield of $60 \%$ ) after 60 minutes hydrolysis time at $120^{\circ} \mathrm{C}$. This clearly indicated that furfural competing reactions were more pronounced at $160^{\circ} \mathrm{C}$. This might also be attributed to the effect of the higher temperature, which reduced hydrogen ion concentration, thus lowering the water dielectric constant and consequently making an insignificant impact of the acid concentration on the furfural formation kinetics data.

\subsection{LSR Parameter}

The effect of LSR at values of 25, 50 and 100 at $120{ }^{\circ} \mathrm{C}$ and $10 \mathrm{wt} \%$ acid concentration on 
the measured furfural concentrations during the hydrolysis reaction was depicted in Fig. 3. Higher LSR values, which implied a lower limiting reactant, decreased the obtained furfural concentration with time. The maximum furfural concentration for all LSRs was obtained at 60 minutes. Moreover, the maximum achievable furfural concentration was decreased from $2097 \mathrm{gm} / \mathrm{m}^{3}$ (50\% furfural yield) to $1266 \mathrm{gm} / \mathrm{m}^{3}$ (60\% furfural yield) and $700 \mathrm{gm} / \mathrm{m}^{3}$ (66\% furfural yield) at LSR of 25 , 50 and 100 respectively since only LSR changed, while the kinetic parameters $\left(\mathrm{k}_{1}-\mathrm{k}_{4}\right)$ remained unchanged at the same reaction temperature and acid concentration.

\subsection{Side Products Formation}

The cost of the furfural production process was considerably influenced by the maximum achievable furfural yield with the accompanied side products. Moreover, the formation of side products required a separation process for a treatment purpose to achieve the desired product specifications. Table 1 summarizes the reaction time required to produce the maximum furfural yield and concentration obtained at different operating conditions, along with the corresponding concentration of furfuryl alcohol, 5 hydroxymethyl furfural (5HMF), 5 methyl furfural $(5 \mathrm{MF})$ and 2 acetyl furan side products. Table 1 shows that the highest achieved furfural yield was $72 \%$, which was produced in 20 minutes at an acid concentration of $15 \mathrm{wt} \%$, LSR of 100 and $120^{\circ} \mathrm{C}$. Figure 4 shows furfural yield at this operating condition measured at different reaction times.

Side products were considered as valuable products, due to their industrial applications. For example, furfuryl alcohol was used for the production of tetrahydrofurfuryl alcohol, fibers, rubbers and for enforcing ceramic resins ${ }^{[34]}$. Also, 5
Hydroxymethyl furfural (5HMF) was used for plastics productions ${ }^{[35]}$. However, it should be noted that the side product content of 5 methyl furfural $(5 \mathrm{MF})$ should be less than $1 \%$ in furfural product specification ${ }^{[7]}$. Side products concentrations with time at the optimum operating condition are shown in Fig. 5.

\subsection{Kinetics Parameters}

Derived nonlinear model presented in Eq. 7 was used to fit the collected kinetic data of furfural yield from palm tree midribs at different experimental conditions. Polymath 5.1 software was used in the nonlinear regression analysis. Table 2 presents the optimum regression analysis values of $\mathrm{k}_{1}$ to $\mathrm{k}_{4}$, and $\alpha$ for all acid hydrolysis reactions at different operating conditions.

Table 2 shows that all $\mathrm{k}$ values increased with reaction temperature and acid concentration. Regressed $\alpha$ values, (0.60-0.94), fell within the same reported ranges of (0.84$0.86)$ and (0.55-1) reported by Eken-Saracoglu et al. ${ }^{[20]}$ and Aguilar et al. ${ }^{[31]}$ respectively. Regression of the experimental data at different acid concentrations and reaction temperatures using Eq. 7 resulted in satisfactory fit, as evidenced by $\mathrm{R}^{2} \geq 0.9$ as shown in Fig. 1-3. The higher value of $k_{1}$ compared to $\mathrm{k}_{2}-\mathrm{k}_{4}$ values indicated a faster rate of pentosan to pentose reaction step, and the reaction steps that followed controlled the final furfural production.

The modified Arrhenius equation was used to estimate the rate constant for a given reaction temperature and acid concentration. It was expressed as follows ${ }^{[9,13,30,31,36]}$.

$$
k_{i}=a C^{b} \exp (-E / R T)
$$

Where $\mathrm{a}$ and $\mathrm{b}$ are regression parameters, $C$ is the acid concentration in wt $\%, E$ is the activation energy in $\mathrm{kJ} / \mathrm{mol}, \mathrm{R}$ is the universal gas constant in $\mathrm{kJ} /(\mathrm{mol} \mathrm{K})$, and $T$ is the reaction temperature in $\mathrm{K}$. 


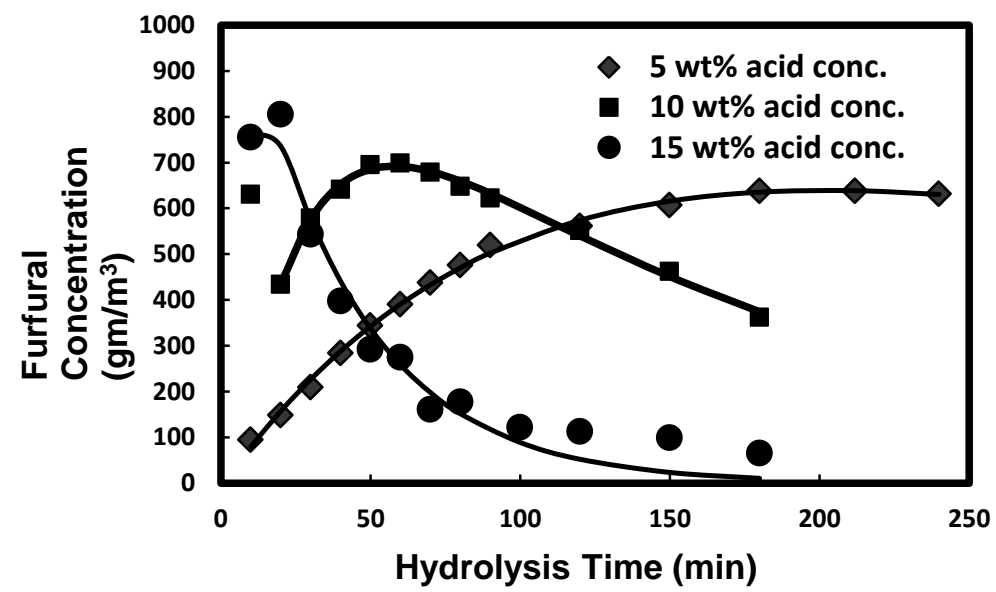

Fig. 1. Date Tree midribs, 0.25-0.5mm, Acid $=\mathrm{HCl}, 5-15 w t \%$, LSR $=100$, Hydrolysis $\mathrm{Temp}=120^{\circ} \mathrm{C}$.

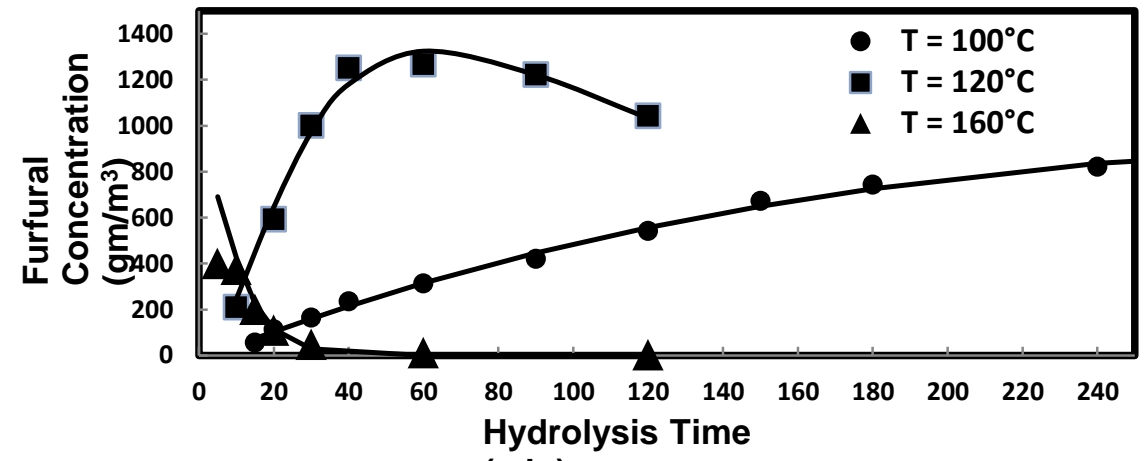

Fig. 2. Date Tree midribs, $0.25-0.5 \mathrm{~mm}$, Acid $=\mathrm{HCl}, 10 \mathrm{wt} \%, 250 \mathrm{ml}$, LSR $=50$ Hydrolysis $\mathrm{Temp}=100-160^{\circ} \mathrm{C}$.

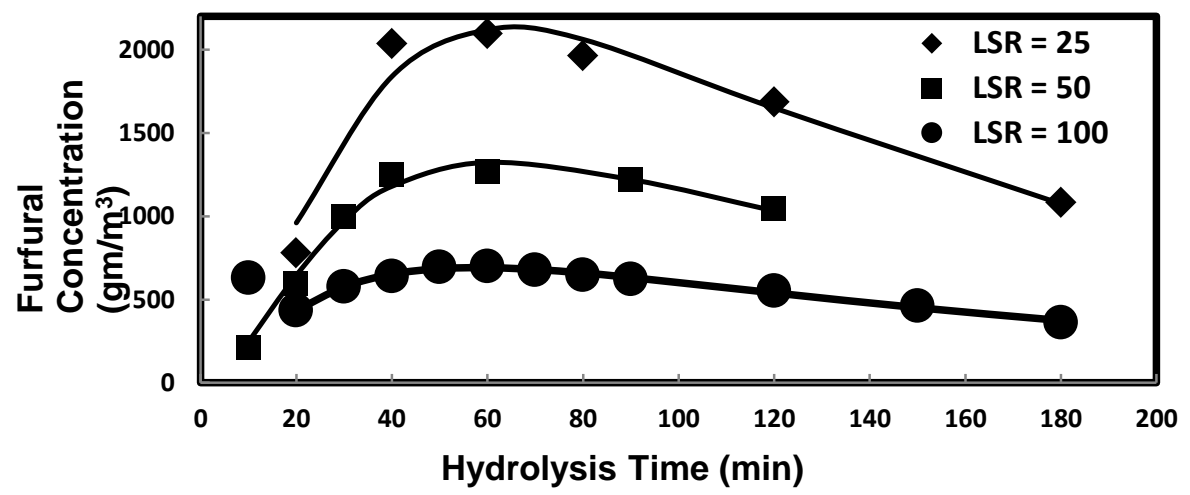

Fig. 3. Date Tree midribs, 0.25-0.5 mm, Acid $=\mathrm{HCl}$, 10wt $\%$, LSR $=25-100$, Hydrolysis $\mathrm{Temp}=120^{\circ} \mathrm{C}$. 
Table 1. Summary of different reaction conditions with corresponding maximum furfural yields and concentrations using hydrochloric acid.

\begin{tabular}{|c|c|c|c|c|c|c|c|c|c|}
\hline \multirow{2}{*}{$\begin{array}{l}\text { Acid } \\
\text { Conc. } \\
\text { (wt\%) }\end{array}$} & \multirow{2}{*}{$\begin{array}{c}\text { LSR } \\
(\mathrm{ml} / \mathrm{g})\end{array}$} & \multirow{2}{*}{$\begin{array}{c}\text { Temp, } \\
\left({ }^{\circ} \mathrm{C}\right)\end{array}$} & \multirow{2}{*}{$\begin{array}{l}\text { Time } \\
\text { (min) }\end{array}$} & \multirow{2}{*}{$\begin{array}{l}\text { Max } \\
\text { Yield } \\
(\%)\end{array}$} & \multirow{2}{*}{$\begin{array}{l}\text { Max Furfural } \\
\text { Concentration } \\
\quad(p p m)\end{array}$} & \multicolumn{4}{|c|}{$\begin{array}{l}\text { Concentration of side products corresponding to } \\
\text { maximum furfural concentration (ppm) }\end{array}$} \\
\hline & & & & & & 5HMF & 5MF & Furfural Alcohol & 2 Acetyl Furan \\
\hline 5 & 100 & 120 & 210 & 60 & 640 & 15 & 2 & 7 & 10 \\
\hline 5 & 100 & 140 & 30 & 41 & 435 & 15 & 2 & 9 & 0 \\
\hline 10 & 25 & 120 & 60 & 50 & 2097 & 70 & 14 & 21 & 7 \\
\hline 10 & 50 & 100 & 330 & 44 & 924 & 16 & 2 & 12 & 4 \\
\hline 10 & 50 & 120 & 60 & 60 & 1266 & 37 & 5 & 12 & 3 \\
\hline 10 & 50 & 160 & 5 & 19 & 400 & 71 & 3 & 9 & 4 \\
\hline 10 & 100 & 120 & 60 & 66 & 700 & 18 & 2 & 8 & 2 \\
\hline 15 & 25 & 120 & 5 & 25 & 1063 & 72 & 1 & 332 & 145 \\
\hline 15 & 100 & 120 & 10 & 72 & 755 & 15 & 2 & 45 & 2 \\
\hline
\end{tabular}

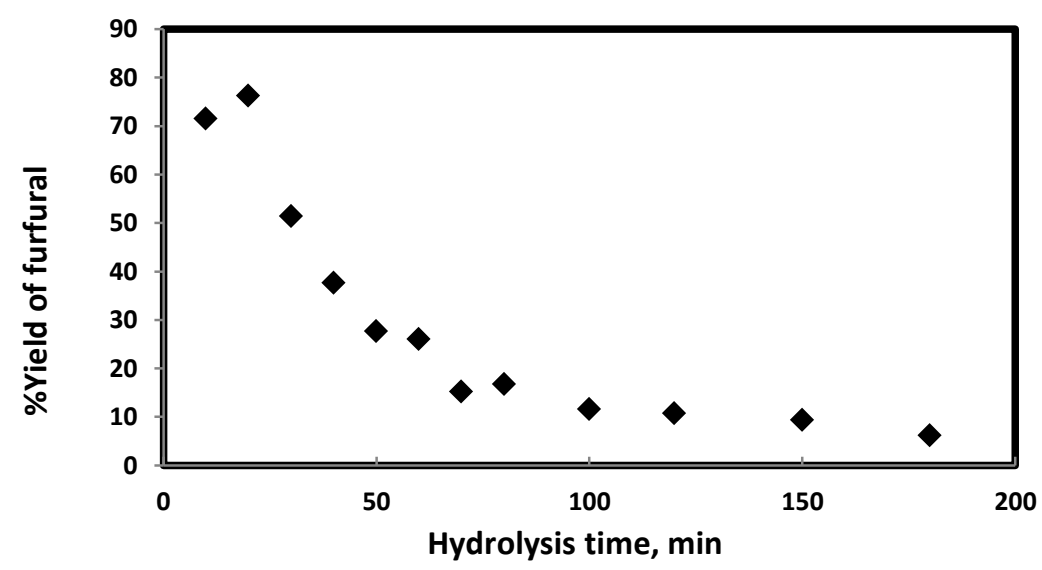

Fig. 4. Furfural yield using $0.25-0.5 \mathrm{~mm}$ date tree midribs, $15 \mathrm{wt} \% \mathrm{HCl}$, LSR=100, Temp $=120^{\circ} \mathrm{C}$.

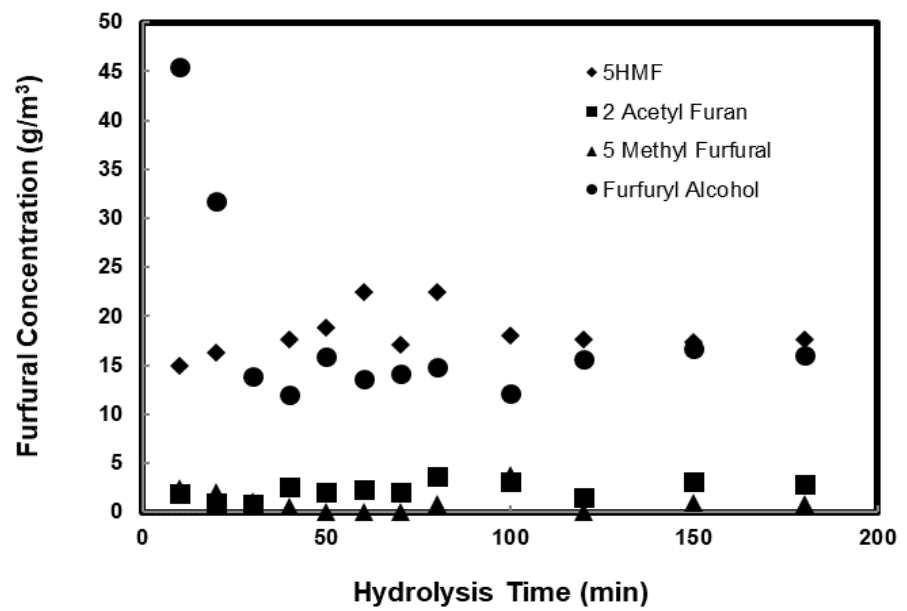

Fig. 5. Side products distribution using $0.25-0.5 \mathrm{~mm}$ date tree midribs, $15 \mathrm{wt} \% \mathrm{HCl}, \mathrm{LSR}=100$, $\mathrm{Temp}^{\circ}=120^{\circ} \mathrm{C}$. 
Table 2. Regression values of k1- $\mathrm{k} 4$ and $\alpha$ at different acid concentrations and temperatures.

\begin{tabular}{|c|c|c|c|c|c|c|c|}
\hline $\mathrm{HCl} \% \mathrm{wt}$ & $\mathrm{T}{ }^{\circ} \mathrm{C}$ & $\alpha . \mathrm{g} / \mathrm{g}$ & $\mathrm{k}_{1}(\mathrm{~min})^{-1}$ & $\mathrm{k}_{2}(\mathrm{~min})^{-1}$ & $\mathrm{k}_{3}(\mathrm{~min})^{-1}$ & $\mathrm{k}_{4}(\min )^{-1}$ & $\mathrm{R}^{2}$ \\
\hline 5 & 120 & 0.600 & 0.111 & 0.015 & 0.001 & 0.001 & 0.99 \\
\hline 5 & 140 & 0.658 & 0.221 & 0.152 & 0.069 & 0.009 & 0.97 \\
\hline 10 & 100 & 0.741 & 0.326 & 0.004 & 0.0001 & 0.003 & 0.99 \\
\hline 10 & 120 & 0.843 & 0.390 & 0.080 & 0.037 & 0.012 & 0.96 \\
\hline 10 & 160 & 0.917 & 0.447 & 0.410 & 0.269 & 0.136 & 0.99 \\
\hline 15 & 120 & 0.940 & 0.996 & 0.136 & 0.065 & 0.031 & 0.99 \\
\hline
\end{tabular}

It is advantageous to validate and compare the model prediction of $\mathrm{k}$ values with reported models in the literature that used closer acid concentrations, temperature ranges and different agricultural wastes. Herrera and his workers ${ }^{[30]}$ proposed the kinetic parameters $\mathrm{k}_{1}$ and $\mathrm{k}_{2}$ for the hydrolysis of sorghum, using 2-6 wt $\% \mathrm{HCl}$ at $122^{\circ} \mathrm{C}$ as follows:

$$
\begin{gathered}
k_{1}=0.00261 C_{a}^{1.41} \\
k_{2}=0.0009 C_{a}^{0.93}
\end{gathered}
$$

Where $C_{a}$ is the wt\% acid concentration. Eq. 9 and 10 underpredict the value of $\mathrm{k}_{1}(0.016$ compared to regressed value of 0.111 ) and $\mathrm{k}_{2}$ (0.004 compared to regressed value of 0.015 ) at $5 \mathrm{wt} \% \mathrm{HCl}$ and $120^{\circ} \mathrm{C}$. This might be due to different raw materials used in both cases and thus different side products.

Since there was no correlation available in literature that was suitable for predicting $\mathrm{k}$ values at acid concentrations higher than 6 wt $\%$, modified Arrhenius correlations to predict $\mathrm{k}_{1}-\mathrm{k}_{4}$, at acid concentrations in the range of 5 to $15 \mathrm{wt} \%$, could be developed by nonlinear regression analysis of $\mathrm{k}$ values at different conditions, using Polymath 5.1 software. The resulted correlations showed satisfactory predictions with the correlation coefficients $\mathrm{R}^{2} \geq 0.96$ as presented in Table 3 .

Table 3. Modified Arrhenius correlations for $\mathbf{k}_{\mathbf{1}}-\mathbf{k}_{\mathbf{4}}$.

\begin{tabular}{|cc|c|}
\hline \multicolumn{2}{|c|}{ Correlations } & $\mathbf{R}^{2}$ \\
\hline$k_{1}=0.0172 \times C^{2.152} e^{\left(-0.5874 \times 10^{4}\right)} / R T$ & $(11)$ & 0.96 \\
\hline$k_{2}=1.01 \times 10^{5} C^{0.749} e^{\left(-5.093 \times 10^{4}\right) / R T}$ & $(12)$ & 0.96 \\
\hline$k_{3}=1.008 \times 10^{4} C^{1.028} e^{\left(-5.49 \times 10^{4}\right) / R T}$ & $(13)$ & 0.96 \\
\hline$k_{4}=9.991 \times 10^{5} C^{1.702} e^{\left(-6.295 \times 10^{4}\right) / R T}$ & $(14)$ & 0.97 \\
\hline
\end{tabular}

Where $\mathrm{C}$ is $\mathrm{HCl}$ concentration in wt $\%, \mathrm{~T}$ is the hydrolysis reaction temperature in Kelvin and $\mathrm{R}$ is the universal gas constant in $\mathrm{kJ} / \mathrm{mol}$ $K$. It was observed from Equation (11) that the pentosan hydrolysis to pentose reaction $\left(\mathrm{k}_{1}\right)$ had the lowest activation energy which indicated that this reaction was the fastest step relative to the other reaction steps and thus highest $\mathrm{k}_{1}$ values. The activation energies for the other reactions were higher than the first reaction, due to lower $\mathrm{k}_{2}-\mathrm{k}_{4}$ values and slower reaction rates accordingly.

Natural $\log$ of $\mathrm{k}_{1}, \mathrm{k}_{2}, \mathrm{k}_{3}$, and $\mathrm{k}_{4}$ versus the reciprocal of the absolute reaction temperature $(1 / \mathrm{T})$ were plotted as shown in Fig. 6 at 10 wt $\%$ acid concentration and LSR of 50. Modified Arrhenius equation was satisfied, since kinetic data were fit in almost straight lines for all $\mathrm{k}$ values with their corresponding reaction temperatures. The low $\mathrm{R}^{2}$ value associated with fitting $\mathrm{k}_{2}$ and $\mathrm{k}_{3}$ are probably due to other side reactions beside $\mathrm{k}_{2}$ and $\mathrm{k}_{3}$ corresponding reaction steps which were not considered in the proposed full reaction configuration.

Romero and his workers ${ }^{[9]}$ proposed a correlation that predicted insoluble fraction, $100(1-\alpha) \mathrm{g} / 100 \mathrm{~g}$ raw material, linearly with temperature and nonlinearly with acid concentration. With an attempt to correlate $\alpha$ regression output of this work with the corresponding temperatures and acid concentrations using similar proposed correlation, the following correlation was obtained: 


$$
\beta=(842.524-4.172 T) C^{-1.299}
$$

Where

$$
\beta=100(1-\alpha)
$$

The regression output for fitting the experimental data with $(5-15 \mathrm{wt} \%) \mathrm{HCl}$ and $\left(100-160^{\circ} \mathrm{C}\right)$ to Eq. 15 yields $\mathrm{R}^{2}=0.95$. The regression parameters of Eq. 15 were quite different from Remero's correlation, which might be attributed to the difference in the raw material composition used in both cases. However, this correlation, beside Eq. (11-14), could be used in the hydrolysis of midribs from date palm tree reactor design.

\section{Comparison with Sulfuric Acid Hydrolysis}

Hydrolysis data of midribs with hydrochloric acid was compared with sulfuric acid hydrolysis data in our previous work ${ }^{[8]}$. The optimum condition obtained with $\mathrm{HCl}$ hydrolysis gave an excellent furfural yield (72\%), which was close to the theoretical yield (72.7\%) at $15 \mathrm{wt} \% \mathrm{HCl}, 120^{\circ} \mathrm{C}$ and $100 \mathrm{LSR}$ compared to $\mathrm{H}_{2} \mathrm{SO}_{4}$ hydrolysis, which gave a furfural yield of $(53 \%)$ at $15 \mathrm{wt} \%$ and $120^{\circ} \mathrm{C}$ and 50 LSR. In addition to the higher furfural yield obtained with $\mathrm{HCl}$ hydrolysis, a lower initial concentration was required as compared to hydrolysis with $\mathrm{H}_{2} \mathrm{SO}_{4}$ (LSR of 100 with $\mathrm{HCl}$ compared to 50 with $\mathrm{H}_{2} \mathrm{SO}_{4}$ ).

Furthermore, faster reactions and higher furfural yields were observed with $\mathrm{HCl}$ acid as compared to $\mathrm{H}_{2} \mathrm{SO}_{4}$ at the same conditions. For example, at $5 \mathrm{wt} \% \mathrm{HCl}$ and $120^{\circ} \mathrm{C}$, maximum furfural yield of $60 \%$ was achieved at 210 minutes, while it took 240 minutes to reach a maximum yield of $22 \%$ at the same conditions with sulfuric acid hydrolysis. Similarly, at $10 \mathrm{wt} \% \mathrm{HCl}$ and $120^{\circ} \mathrm{C}$ the maximum furfural yield of $60 \%$ was achieved at 60 minutes as compared to 180 minutes to reach a maximum yield of $25 \%$ at the same conditions. Increasing $\mathrm{HCl}$ concentration from 5 to $15 \mathrm{wt} \%$ expedited the reaction significantly, while in the case of $\mathrm{H}_{2} \mathrm{SO}_{4}$ the concentration increase did not affect the hydrolysis time, until $15 \%$ was used. On the other hand, increasing the temperature with $\mathrm{HCl}$ hydrolysis caused faster reactions and higher furfural yields than $\mathrm{H}_{2} \mathrm{SO}_{4}$ hydrolysis. This could be attributed to lower activation energy values for furfural formation reactions steps with $\mathrm{HCl}$ as compared to the corresponding ones using $\mathrm{H}_{2} \mathrm{SO}_{4}$ hydrolysis as shown in Table 4. The activation energy for the reaction steps $k_{1}$ through $k_{4}$ are estimated from the natural exponential term $\left(\mathrm{e}^{-\mathrm{E} / \mathrm{RT}}\right)$ in the Equations 11 through 14 respectively.

So, hydrolysis of palm tree midrib in hydrochloric acid produced more furfural as compared to sulfuric acid, and hence it was recommended to consider the application of hydrochloric acid with higher concentrations as a catalyst in the industrial hydrolysis process of palm tree midribs to achieve higher yields and produce more desirable furfural products.

\section{Conclusions}

Furfural could be produced by $\mathrm{HCl}$ hydrolysis of pentosane that exists in palm tree midribs as an agricultural waste with an achievement of $72 \%$ maximum furfural yield. This actual yield was close to the theoretical yield $(72.7 \%)$ at reaction conditions of temperature as $120^{\circ} \mathrm{C}$, acid concentration as 15 $\mathrm{wt} \%$ and LSR as 100. Experimental data showed that furfural yield is function of reaction temperature, acid concentration and LSR. The kinetic model of the furfural production reactions that was derived in a previous work was used in the regression of the experimental furfural concentrations obtained in this work with acceptable predictions and regression coefficients of $R^{2} \geq 0.96$. Furthermore, the rate constants of the reaction steps as well as the hydrolyzed fraction were correlated using modified Arrhenius model at the reaction conditions. The derived correlations could provide a 
preliminary design basis for the optimization of the hydrolysis reactor configuration. Finally, comparison with the sulfuric acid hydrolysis showed that using hydrochloric acid higher furfural yields were achieved and lower reaction times were required due to lower activation energy of the involved step.

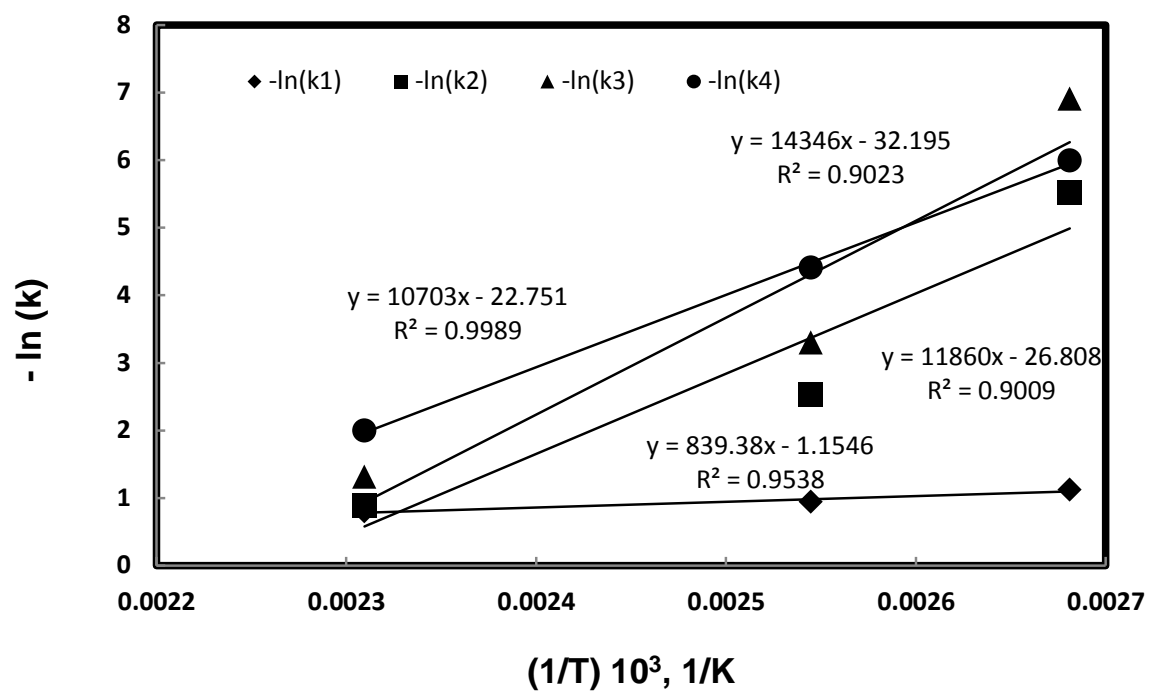

Fig. 6. Fitting $k_{1}-k_{4}$ values with (1/T) at $10 \mathrm{wt} \% \mathrm{HCl}$.

Table 4. Activation energy comparison for the reactions steps with $\mathrm{HCl}$ and $\mathrm{H}_{2} \mathrm{SO}_{4}$.

\begin{tabular}{|c|c|c|}
\hline \multirow{2}{*}{$\begin{array}{c}\text { Reaction } \\
\text { Step }\end{array}$} & \multicolumn{2}{|c|}{ Activation Energy, $\mathrm{kJ} / \mathrm{mol}$} \\
\cline { 2 - 3 } & $\begin{array}{c}\text { With } \mathrm{HCl} \\
\text { This work }\end{array}$ & $\begin{array}{c}\text { With } \mathrm{H}_{2} \mathrm{SO}_{4} \\
\text { (Bamufleh } \text { et al. } \text { ) }\end{array}$ \\
\hline $\mathrm{k}_{1}$ & 5.87 & 15.99 \\
\hline $\mathrm{k}_{2}$ & 50.93 & 94.97 \\
\hline $\mathrm{k}_{3}$ & 54.90 & 127.6 \\
\hline $\mathrm{k}_{4}$ & 62.95 & 59.54 \\
\hline
\end{tabular}

\section{Acknowledgments}

The authors are grateful for the support of the King Abdulaziz City for Science and Technology (KACST), Grant No. AR 27-107.

\section{References}

[1] Mansilla, H.D., Baeza, J., Urzua, S., Muturana, G., Villasenor, J. and Duran, N. (1998). "Acidcatalyzed hydrolysis of rice hull: Evaluation of furfural production", Bioresource Technology, 66: 189-193.

[2] Brydson, J.A. (1999). Plastic Materials, $7^{\text {th }}$ ed., Butterworth Heinemann, pp: 810-813.

[3] Ibeh, C. C. (1999). "Amino and furan resins", In:
S.H. Goodman (Ed.), Handbook of Thermoset Plastics (2), 72-96, William Andrew.

[4] Merlo, A.B., Vetere, V., Ruggera, J.F. and Casella, M L. (2009). "Bimetallic PTSn catalyst for the selective hydrogenation of furfural to furfuryl alcohol in liquid-phase", Catalysis Communications, 10: 1665-1669.

[5] Danon, B., Hongsiri, W., Aa, L. and Jong, W. (2014). "Kinetic study on homogeneously catalyzed xylose dehydration to furfural in the presence of arabinose and glucose", Biomass \& Bioenergy, 66: 1-7.

[6] Yan, K., Wu, G., Lafleur, T. and Jarvis, C. (2014). "Production, properties and catalytic hydrogenation of furfural to fuel additives and value-added chemicals", Renewable and Sustainable Energy 
Reviews, 38: 663-676

[7] Zeitsch, K.J. (2000). "Furfural production needs chemical innovation", Chemical Innovation, 30(4): 29-32.

[8] Bamufleh, H.S., Alhamed, Y.A. and Daous, M.A (2013). "Furfural from midribs of date-palm trees by sulfuric acid hydrolysis", Industrial and Crops Production, 42: 421-428.

[9] Romero, I., Ruiz, E., Castro, E. and Moya, M. (2010). "Acid hydrolysis of olive tree biomass", Chemical Engineering Research and Design, 88: 633-640.

[10] Vazquez, M., Oliva, M., Tellez-Luis, S.J. and Ramirez, J.A. (2007). "Hydrolysis of sorghum straw using phosphoric acid: Evaluation of furfural production", Bioresource Technology, 98: 3053-3060.

[11] Yat, S.C., Berger, A. and Shonnard, D.R. (2008). "Kinetic characterization for dilute sulfuric acid hydrolysis of timber varieties and switch grass", Bioresource Technology, 99: 3855-3863.

[12] Gamez, S., Gonzalez-Cabriales, J.J., Ramirez, J.A., Garrote, G. and Vazquez, M. (2006). "Study of the hydrolysis of sugar cane bagasse using phosphoric acid", J. Food Eng., 74: 78-88

[13] Rodriguez, G., Lama, A., Rodriguez, R., Jimenez, A., Guillen, R. and Fernandez-Bolanos, J. (2008). "Review: olive stone an attractive source of bioactive and valuable compounds", Bioresource Technology, 99: 5261-5269.

[14] Mao, L., Zhang, L., Gao, N. and Li, A. (2012). " $\mathrm{FeCl}_{3}$ and acetic acid co-catalyzed hydrolysis of corncobs for improving furfural pridution and lignin removal from residue", Bioresource Technology, 123: 324-331.

[15] Herrera, A., Tellez-Luis, S.J., Gonzalez-Cabriales, J.J., Ramirez, J.A. and Vazquez, M. (2004). "Effect of the hydrochloric acid concentration on the hydrolysis of the sorghum at atmospheric pressure", J. Food Eng., 63: 103-109.

[16] Rodriguez-Chong, A., Ramirez, J.A., bura, G. and Vazquez, M. (2004). "Hydrolysis of sugar cane bagasse using nitric acid: a kinetic assessment", $J$. Food Eng., 61: 143-152.

[17] Suxia, R., Haiyan, X., Jinling, Z., Shunqing, L., Xiafeng, H. and Tingzhou, L. (2012). "Furfural production from rice husk using sulfuric acid and a solid acid catalyst through a two-stage process", Carbohydrate Research, 359: 1-6.

[18] Lenihan, P., Orozco, A., O'Neill, E., Ahmad, M.N.M., Rooney, D.W. and Walker, G.M. (2010). "Dilute acid hydrolysis of lignocelluloses biomass", Chem. Eng. J., 156: 395-403.

[19] Karimi, K., Kheradmandinia, S. and Taherzadeh, M., J. (2006). "Conversion of rice straw to sugar by dilute acid hydrolysis," Biomass Bioenergy, 30: 247-
253.

[20] Eken-Saracoglu, N., Mutlu, S.F., Dilmac, G. and Cavusogly, H. (1998). "A comparative kinetic study of acid hemicelluloses hydrolysis in corncob and sunflower seed hull", Bioresource Technology, 65: 29-33.

[21] Montane, D., Salvado, J., Torras, C. and Farriol, X. (2002). "High-temperature dilute-acid hydrolysis of olive stones for furfural production", Biomass Bioenergy, 22: 295-304.

[22] Peleteiro, S., Rivas, S., Alonso, J. L., Santos, V. and Parajo, J., C. (2016). "Furfural production using an acidic ionic liquids: A review", Bioresource Technology, 202: 181-191.

[23] Yemis, O. and Mazza, G. (2012). “Optimization of furfural and 5-hydroxymethylfurfural production from wheat straw by a microwave-assisted process", Bioresource Technology, 109: 215-223.

[24] Agirrezabal-Telleria, I., Gandarias, I. and Arias, P.L. (2014). "Heterogeneous acid-catalysts for the production of furan-derived compounds (furfural and hydroxymethylfurfural) from renewable carbohydrates: A review", Catalysis Today, 234: 42-58.

[25] Kaiprommarat, S., Kongparakul, S., Reubroycharoen, P., Guan, G. and Samart, C. (2016). "Highly efficient sulfonic MCM-41 catalyst for furfural production: furan-based biofuel agent", Fuel, 174: 189-196.

[26] Zhang, T., Li, W., Xu, Z., Liu, Q., Ma, Q., Jameel, H., Chang, H.M. and Ma, L. (2016). "Catalytic conversion of xylose and corn stalk into furfural over carbon solid acid catalyst in gamma-valerolactone", Bioresource Technology, 209: 108-114.

[27] Zhang, L., Guoyun Xi, G., Zhang, L., Yu, H. and Wang, X. (2017). "Efficient catalytic system for the direct transformation of lignocellulosic biomass to furfural and 5-droxymethylfurfural", Bioresource Technology, 224: 656-661.

[28] Deng, A., Lin, Q., Yan, Y., Li, H., Ren, J., Liu, C. and Sun, R. (2016). "A feasible process for furfural production from the pre-hydrolysis liquor of corncob via biochar catalysts in a new biphasic system", Bioresource Technology, 216: 754-760.

[29] Jeon, W., Ban, C., Kim, J., E., Woo, H., C. and Kim, D., H. (2016). "Production of furfural from macroalgae-derived alginic acid overAmberlyst-15", Journal of Molecular Catalysis A: Chemical, 423: 264-269.

[30] Herrera, A., Tellez-Luis, S.J., Ramirez, J.A. and Vazquez, M. (2003). "Production of xylose from sorghum straw using hydrochloric acid", J. Cereal Sci., 37: 267-274.

[31] Aguilar, R., Ramirez, J.A., Garrote, G. and Vazquez, M. (2002). "Kinetic study of the acid hydrolysis of sugar cane bagasse", J. Food Eng. 55: 
309-318.

[32] Sánchez, C., Serrano, L., Andres, M.A. and Labidi, J. (2013). "Furfural production from corncobs autohydrolysis liquors by microwave technology", Industrial Crops and Products, 42: 513-519.

[33] Laopaiboon, P., Thani, A., Leelavatcharamas, V. and Laopaiboon, L. (2009). "Acid hydrolysis of sugarcane bagasse for lactic acid production", Bioresource Technology, 101: 1036-1043.

[34] Huang, W., Li, H., Zhu, B., Feng, Y., Wang, S. and Zhang, S. (2007). "Selective hydrogenation of furfural to furfuryl alcohol over catalysts prepared via sonochemistry", Ultrasonics Sonochemistry, 14: 6774.

[35] Fujiki, J., Fan, H., Hattori, H., Tajima, K., Tsia, Y. and Furuya, E. (2008). "Computer-aided design of surface modified adsorbent for adsorption of 5hydroxy-methyl-furfural", Separation and Purification Technology, 60: 223-229.

[36] Tellez-Luiz, S.J., Ramirrez, J.A. and Vazquez, M. (2002). "Mathematical modeling of hemicellulosic sugar production from sorghum straw", J. Food Eng. 52: 285-291. 


\section{التحلل المائي لسعف شجرة النخيل في حمض الهيدروكلوريك لإنتاج مادة الفورفورال هشام سعيد بامفلح}

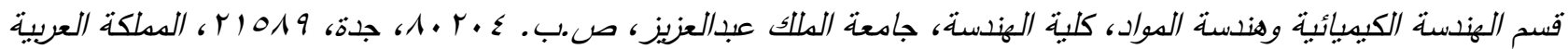
السعودية

hbamufleh@kau.edu.sa

المستخلص. نم جمع عينات من مخلفات سعف النخيل من نوع السكري كمدر للبنتوزان من

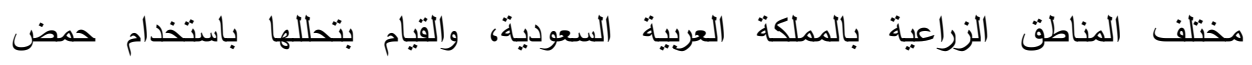

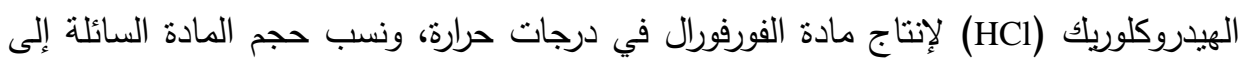
وزن العينة الصلبة (LSR) وتراكيز حمض مختلفة. أنتجت مادة الفورفورال كد أقصى بتركيز

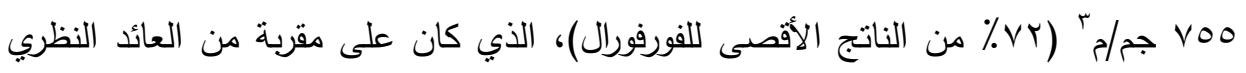

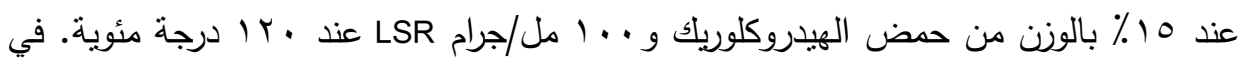
دراسة سابقة نم اقتراح وتطوير النموذج الرياضي للتحلل الجزئي للبنتوزان لإنتاج الفورفورال.

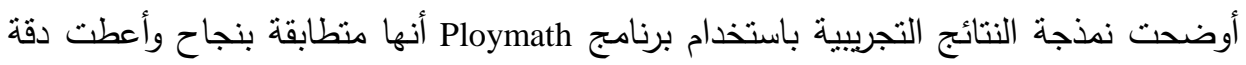

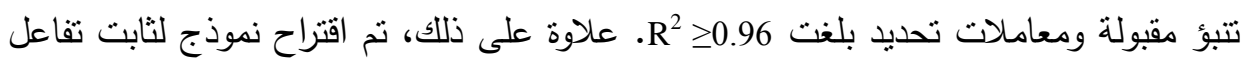
كل خطوة باستخدام نموذج Arrhenius المعدل بدقة مقبولة ومعاملات تحديد بلغت كما أظهرت النتائج التجريبية أن التحلل المائي باستخدام حمض الهيدروكلوريك يمكن أن ينتج كميات فورفورال أعلى في أوقات أقل بالمقارنة مع تحلل حمض الكبريتيك، وذللك بسبب انخفاض باض

طاقة النتشيط للخطوة المعنية. كلمات مفتاحية: فورفورال، سعف النخيل، حمض الهيدروكلوريك، التحلل المائي. 
